Pathogens Are Linked to Human Moral Systems Across Time and Space

Mohammad Atari ${ }^{1,2}$, Nils K. Reimer ${ }^{1,2}$, Jesse Graham ${ }^{3}$, Joe Hoover ${ }^{1,2}$, Brendan Kennedy ${ }^{2,4}$, Aida Mostafazadeh Davani ${ }^{2,4}$, Farzan Karimi-Malekabadi ${ }^{1,2}$, Shirin Birjandi ${ }^{1,5}$, and Morteza Dehghani ${ }^{1,2,4}$

${ }^{1}$ Department of Psychology, University of Southern California

${ }^{2}$ Brain and Creativity Institute, University of Southern California

${ }^{3}$ Department of Management, David Eccles School of Business, University of Utah

${ }^{4}$ Department of Computer Science, University of Southern California

${ }^{5}$ Department of Biological Sciences, University of Southern California

Author Note

Correspondence regarding this article should be addressed to Mohammad Atari, atari@usc.edu, 362 S. McClintock Ave, Los Angeles, CA 90089-161. This research was sponsored by NSF CAREER BCS-1846531. 


\begin{abstract}
Infectious diseases have been an impending threat to the survival of individuals and groups throughout our evolutionary history. As a result, humans have developed psychological pathogen-avoidance mechanisms and groups have developed societal norms that respond to the presence of disease-causing microorganisms in the environment. In this work, we demonstrate that morality plays a central role in the cultural and psychological architectures that help humans avoid pathogens. We present a collection of studies which together provide an integrated understanding of the socio-ecological and psychological impacts of pathogens on human morality. Specifically, in Studies 1 (2,834 U.S. counties) and 2 (67 nations), we show that regional variation in pathogen prevalence is consistently related to aggregate moral Purity. In Study 3, we use computational linguistic methods to show that pathogen-related words co-occur with Purity words across multiple languages. In Studies $4(n=513)$ and $5(n=334)$, we used surveys and social psychological experimentation to show that pathogen-avoidance attitudes are correlated with Purity. Finally, in Study 6, we found that historical prevalence of pathogens is linked to Care, Loyalty, and Purity. We argue that particular adaptive moral systems are developed and maintained in response to the threat of pathogen occurrence in the environment. We draw on multiple methods to establish connections between pathogens and moral codes in multiple languages, experimentally induced situations, individual differences, U.S. counties, 67 countries, and historical periods over the last century.

Keywords: Morality, Culture, Pathogen Avoidance, Infectious Diseases, Moral Foundations Theory, Behavioral Immune System
\end{abstract}




\section{Pathogens Are Linked to Human Moral Systems across Time and Space}

Humans currently suffer, and have suffered over their evolutionary history, from infectious diseases. Some of these infectious agents have found their way into human populations relatively recently (e.g., human immunodeficiency virus), but many others are of considerable antiquity, suggesting that disease-causing pathogens have posed debilitating threats to human populations through their evolutionary past (Schaller \& Murray, 2011). The presence of strong biological anti-pathogenic mechanisms in humans, as well as other primate populations, is a testament to the power of pathogens and their role in our evolution. The most well-known mechanism to mitigate pathogenic threats is the body's own immune system, whose overall function is to prevent or limit infections after the disease-causing agents have breached the body.

Although the human immune system is vital, its activation is not without costs. For example, activation of the immune system in response to detection of pathogenic microbes is metabolically taxing, robbing individuals of caloric resources that can otherwise be devoted to other evolutionarily important tasks such as searching for desirable mates, caring for one's kin, and building social ties (Schmid-Hempel, 2003). Thus, it is advantageous for the body to prevent its immune system from being chronically burdened by fighting pathogenic microbes. Immunological defenses in response to pathogens occur only after pathogenic agents have compromised the body's immune surveillance system (i.e., reactive defense). Because of the costs associated with generating an adaptive immune response (versus innate), there would have been evolutionarily unique benefits associated with proactive defense: the behavioral prevention of infection by avoiding infectious diseases (Schaller, 2006; Schaller \& Park, 2011). 
The behavioral immune system consists of a suite of psychological mechanisms that detect cues of infectious pathogens in the environment, trigger disease-relevant psychological responses, and facilitate behavioral avoidance of pathogens (Schaller \& Park, 2011). If the socalled behavioral immune system evolved to facilitate specific behavioral responses (e.g., avoidance), it may be considered to be a psychologically unique motivational system (Neuberg et al., 2011). Distinct motivational systems are typically associated with distinct affective experiences (Damasio, 2019; Damasio \& Carvalho, 2013). The affective experience associated with the behavioral immune system has been found to be disgust. There is a substantial body of research implicating the specific role of disgust as a key component of the behavioral immune system (Curtis et al., 2011). The functional relationship between pathogenic agents and disgust manifests in many ways. Specifically, sensory cues that clearly connote proximity to infectious pathogens are especially likely to evoke disgust. Furthermore, behaviors that violate normative expectations in social interactions that are associated with disease transmission (e.g., food preparation, physical proximity, personal hygiene, sexual interaction) can also elicit disgust (Rozin et al., 2008).

Disgust shares some characteristics with other negative affective experiences (e.g., fear, anger, hate), but has a unique influence on information processing systems, which contribute to keeping individuals away from communicable diseases. At the information-processing level, visual attention is engaged for longer periods of time following disgust-eliciting stimuli, compared with neutral or fear-eliciting stimuli, because covert processes automatically initiate the evaluation of pathogen threats (Perone et al., 2021). Disgust can be elicited by objects, such as open wounds, unclean spaces, and dirt, but also by specific forms of social behavior. These behaviors can include unusual sexual acts, eating unusual food, and actions that violate moral 
codes of conduct (Haidt et al.,1994; Tybur et al., 2013; Wagemans et al., 2018). Consistently, some religions attach moral impurity to particular sexual acts (e.g., extramarital relationships), certain food choices (e.g., eating pork), and touching unclean objects such as urine or feces. Moral psychologists have argued that individuals who are more prone to experiencing pathogeninduced disgust may condemn moral violations more strongly, and may be more likely to value practices associated with moral purity such as temperance, chastity, piety, and cleanliness (Haidt \& Joseph, 2004).

In addition to the mentioned individual-level effects of pathogens on cognitive, emotional, and behavioral tendencies, infectious diseases have been found to shape important society-level outcomes. Pathogen prevalence, as an important ecological factor, can influence cultural and moral systems at the community level (e.g., Bastian et al., 2019; Jackson et al., 2019). For example, cross-cultural research suggests that in geographical regions characterized by historically higher pathogen prevalence, people are less individualistic, exhibit lower levels of openness to new things, and more strongly endorse values that emphasize traditionalism, group loyalty, obedience, and respect for authority (Murray et al., 2013; Tybur et al., 2016; Van Leeuwen et al., 2012). In addition, higher historical pathogen prevalence has been linked to higher society-level conformity pressures (i.e., cultural tightness), higher political conservatism, and linguistic heterogeneity (Schaller \& Murray, 2011). There is accumulated evidence suggesting that societies adopt varying rituals and moral values to facilitate coping with chronic prevalence of pathogens (Fincher \& Thornhill, 2012), or large-scale temporary increases in the occurrence of a disease such as the 1918 influenza pandemic (Alexander, 2019). Historians of medicine have proposed, using qualitative data, that epidemics are typically followed by changes 
in social and moral norms, for example increased religiosity, presumably to attenuate the effects of high rates of communicable disease in the environment (Snowden, 2019).

In this work, drawing principally on psychology, anthropology, and behavioral ecology (see Sng et al., 2018), we propose that at the individual level, pathogenic cues are related to moral judgments across individuals and experimental situations. At the society level, we predict that pathogen prevalence is linked to human moral systems across regions, cultures, languages, and historical periods. Specifically, we rely on Moral Foundations Theory (MFT; Graham et al., 2013; Haidt \& Joseph, 2004) to operationalize human moral systems from a cultural and evolutionary perspective. MFT aims to achieve a parsimonious basis for explaining the links between anthropological and evolutionary accounts of moral intuitions. This framework suggests that moral intuitions derive from innate psychological mechanisms that coevolved with cultural institutions. Care, Fairness, Loyalty, Authority, and Purity — according to MFT (Graham et al., 2013) — are moral systems that possess evolutionarily adaptive underpinnings present in individuals across cultures, with each moral system producing automatic "gut-level" reactions of like or dislike when certain phenomena are perceived in the social world, which in turn guide moral judgments of right and wrong. Moral foundations are phenotypically plastic, i.e., although these five foundations have adaptive fitness benefits and are present across human populations, they are environmentally sensitive such that each foundation can be increased or decreased based on the ecologically recurrent problems they can solve. In addition, moral foundations are context-dependent, i.e., although each individual values these foundations to some extent, contextual cues can subtly change people's gut-level judgments in these domains. For example, while conservatives typically value Care and Fairness less than liberals (Graham et al., 2013), 
their score increases on these foundations when analytic thought is activated using immediate contextual cues (Yilmaz \& Saribay, 2017).

Care is rooted in the instinct to protect and nurture offspring and weak individuals in one's group. Fairness is oriented toward concerns of justice, proportionality, equality, and reciprocity. Care and Fairness are collectively referred to as "individualizing" foundations as they are concerned with the rights of individuals (Graham et al., 2011). Loyalty is geared toward concerns of unity, solidarity, togetherness, family, and tribe. Authority values function to defend authority and social order within a hierarchical structure. Finally, Purity corresponds to physical and spiritual cleanliness, decency, and dignity, valuing sacredness, and suppressing carnal desires. Loyalty, Authority, and Purity are collectively referred to as "binding” foundations as they support and enable group ties while discouraging selfish behavior for the good of the group (Graham et al., 2011). While MFT is a cultural and evolutionarily informed theory of human morality, only recently has research begun to test historical-evolutionary causal mechanisms that account for temporal variations in these moral systems (see Muthukrishna et al., 2021).

Here, our overarching theory is that pathogen threat and prevalence are linked to individual-level and population-level endorsements of moral foundations, particularly Purity. Specifically, we argue that Purity is a particular moral system developed and maintained in response to the threat of chronic and acute pathogen occurrence in the environment. We expect that the connection between pathogens and moral Purity should be manifest in contextual judgments and individual differences at individual-level. Since Purity concerns are related to physical proximity-seeking behavior within groups, less unrestricted sexual activity with outgroup members, and higher cleanliness in interpersonal interactions (see Wagemans et al., 
2018), we hypothesize higher endorsements of Purity values in societies that have (or have historically had) high levels of pathogen prevalence.

In Studies 1 and 2, we use epidemiological data to examine how pathogen prevalence is linked to moral systems across geographical regions. We hypothesize that regions with higher prevalence of infectious diseases employ community-level moral concerns, particularly Purity, to cope with (and hopefully reduce) the presence of communicable diseases. For example, an outbreak of an infectious disease in a region can cause residents to lessen social contact, exclude unknown outgroup members (especially those who are perceived to be from the same origin as the disease) through fear of contagion (Kim et al., 2016), care more for immunocompromised persons, and reduce unsafe sexual activity such as short-term sexual encounters. Complementing Studies 1 and 2, in Study 3 we test the hypothesis that if pathogens are accompanied by a particular type of moral system, they should also be linguistically concomitant. In Studies 4 and 5, we investigate our individual-level hypotheses. Specifically, we test whether individuals who generally are more avoiding of pathogenic stimuli value particular moral foundations, and whether pathogenic stimuli are able to activate pathogen-neutralizing moral systems related to physical distancing with unknown individuals, unsafe sexual activities, and cleanliness. Lastly, in Study 6, we explore the historical relationship between rates of infectious diseases and moral language as manifested in the $20^{\text {th }}$ century books.

\section{Study 1}

In this study, we examine the covariation of moral values and pathogen prevalence in geographical regions. The prevalence of infectious diseases specific to each socio-ecology influences moral values in that region. Thus, it is crucial to examine how geographic variation in pathogen prevalence is associated with regional differences in moral values. To test this 
prediction, in Study 1 we investigate the relationship between pathogen prevalence at county level in the U.S. and moral values held in those counties, controlling for county-level political ideology.

\section{Methods}

Pathogen Prevalence. We use county-level pathogen estimates based on infectious diseases data made available by the Centers for Disease Control and Prevention (CDC). The CDC's website (cdc.gov) has information on various infectious (and noninfectious) diseases in the U.S. and provides county-level occurrences of pathogen-related mortality. We used available archival data ${ }^{1}$ from 1999 to 2016 and compiled a data set with county-level mortality rate (per 100,000 residents) due to infectious diseases in 2,834 unique counties $(M=23.8, S D=9.0)$ across 50 states and the District of Columbia (DC).

Moral Values. We used the estimates of county-level distribution of moral values provided by Hoover et al. (2021). These authors relied on data $(N=106,465)$ from www.YourMorals.org, which is an online platform for collecting data on moral values using the Moral Foundations Questionnaire (MFQ; Graham et al., 2011). MFQ is a self-report measure of moral foundations with 30 items measuring the five moral foundations. Although this is a relatively large sample, it cannot be used to directly estimate county-level moral values as it does not use probability sampling at the county level (Hoover \& Dehghani, 2020), and many counties have very few respondents. To address these estimation issues, Hoover et al. (2021) used Multilevel Regression and Synthetic Poststratification (MrsP; Leemann \& Wasserfallen, 2017), a model-based approach for sub-national estimation that extends Multilevel Regression and

\footnotetext{
${ }^{1} \mathrm{http}: / /$ wonder.cdc.gov/ucd-icd10.html
} 
Poststratification (MrP; Park et al., 2004). Specifically, county-level estimates were based on the inclusion of a more diverse set of demographic variables. These estimates also

\section{Figure 1}

Maps showing county-level pathogen prevalence and moral concerns
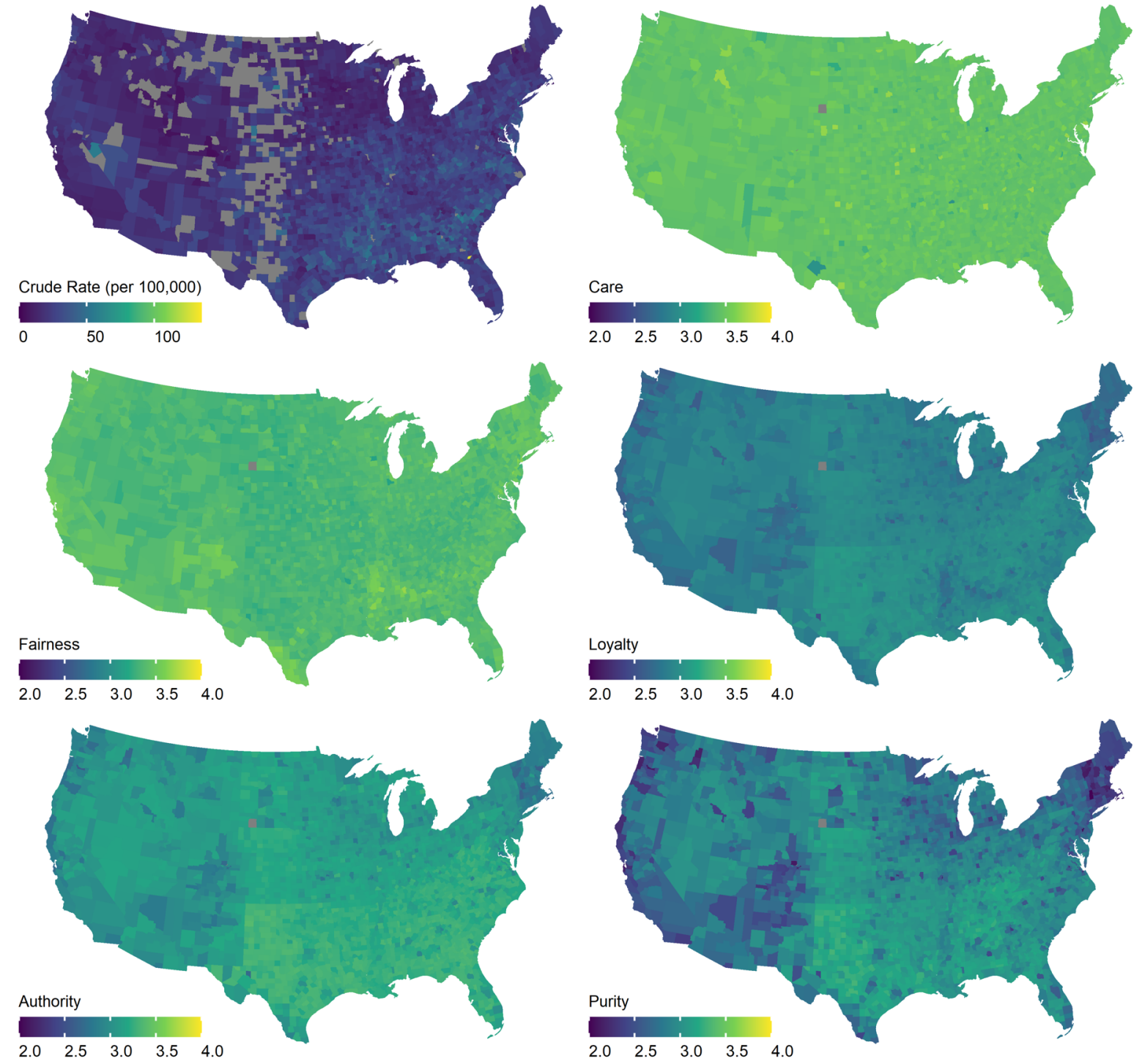

account for two levels of regional clustering, the county level and the region level, and include the proportion of Democratic votes as a county-level factor. Finally, the multilevel model also includes a hierarchical auto-regressive prior (Riebler et al., 2016) that, under the presence of 
spatial auto-correlation, induces local spatial smoothing between proximate counties (Hanretty et al., 2016; Hoover \& Dehghani, 2020; Selb \& Munzert, 2011). We used estimates of Care, Fairness, Loyalty, Authority, and Purity for each county. County-level moral values estimated by Hoover et al. (2021) can be viewed at mapyourmorals.usc.edu.

Political Ideology. Since political ideology is related to both pathogen avoidance (Tybur et al., 2016) and moral values (Graham et al., 2009; Kivikangas et al., 2021), we controlled for the role of political ideology in our statistical models. We collected data from presidential elections in the U.S. (MIT Election Data and Science Lab, 2018) and calculated a county-level conservatism index by subtracting the voters for the Democratic party from the Republican party and dividing that by the total voters (including for the Green party) in that county. We then averaged these county-level conservatism estimates for the same periods as with our pathogen data $(2000,2004,2008,2012,2016$, and 2020 elections). This method for quantifying countylevel conservatism based on voting behavior has been previously used in Karimi-Malekabadi et al. (2021).

Analytic Procedure. To test our hypotheses, we ran five linear regression models that estimated each of the five moral foundations as a function of county-level pathogen prevalence and political conservatism. To better compare regression coefficients, we $z$-standardized all outcome and predictor variables. Our models included a spatial autocorrelation component to account for the tendency of neighboring counties to resemble each other and a non-spatial component to capture residual variation across counties (Besag, 1974; Morris et al., 2019). Our models also included a varying (random) intercept to account for differences in policies, resources, and other factors between states (and the District of Columbia) that were not captured by the predictor variables. 


\section{Figure 2}

Results from the geospatial linear regression models estimating each of the five moral foundations as a function of pathogen prevalence and political conservatism

A

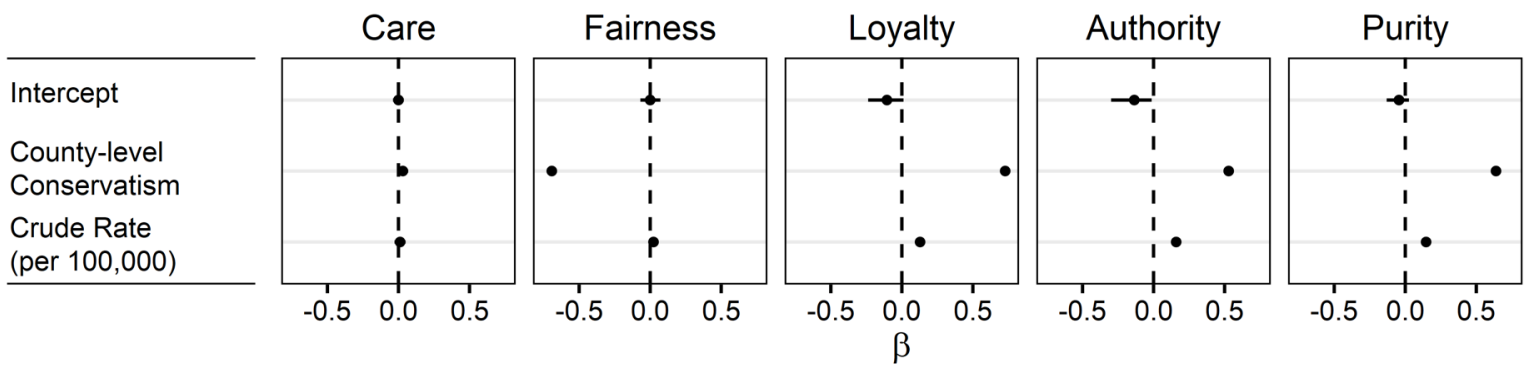

B

\begin{tabular}{|c|c|c|c|c|c|}
\hline & Care & Fairness & Loyalty & Authority & Purity \\
\hline$R^{2}$ & $0 \%[0 \%, 1 \%]$ & $50 \%[48 \%, 52 \%]$ & $60 \%[58 \%, 61 \%]$ & $35 \%[32 \%, 37 \%]$ & $51 \%[49 \%, 53 \%]$ \\
\hline$S D_{\text {State }}$ & $0.03[0.00,0.09]$ & $0.21[0.15,0.29]$ & $0.39[0.28,0.55]$ & $0.43[0.26,0.63]$ & $0.22[0.16,0.32]$ \\
\hline$S D_{\text {County - Spatial }}$ & $0.04[0.00,0.17]$ & $0.39[0.31,0.47]$ & $0.35[0.29,0.42]$ & $0.44[0.37,0.51]$ & $0.44[0.38,0.50]$ \\
\hline$S D_{\text {County - Residual }}$ & $1.00[0.97,1.02]$ & $0.56[0.54,0.58]$ & $0.36[0.34,0.38]$ & $0.38[0.36,0.40]$ & $0.35[0.33,0.37]$ \\
\hline
\end{tabular}

Note. Point estimates with 95\% uncertainty intervals for (A) all regression coefficients as well as for (B) the withinsample variance explained and the standard deviations for the variance across states and the spatial and non-spatial components of the variance across counties.

To estimate these models, we used the brms R package (Bürkner, 2017, 2018) as an interface to fit Bayesian generalized linear multilevel models in Stan (Stan Development Team, 2021). Bayesian inference involves choosing a likelihood function and prior distributions. The likelihood function links the observed data to one or more model parameters (e.g., regression coefficients) by expressing how likely the observed data would have been for different values of said model parameters. Our models used a normal likelihood function. Prior distributions state how plausible different values of said model parameters are before considering the observed data. Our models used weakly informative prior distributions, $\beta \sim$ (Half-)Student- $\mathrm{t}(3,0,2.5)$, for the fixed intercept, the regression coefficients, as well as the standard deviations of the varying intercept and the spatial and residual county-level variances. Bayesian inference applies Bayes' 
theorem to update prior distributions in light of the observed data to produce posterior distributions. Posterior distributions state how plausible different values of the model parameters are given the observed data. We report point estimates, based on the median of posterior samples, and $95 \%$ uncertainty intervals, based on the quantiles of posterior samples, for relevant model parameters. We also report a Bayesian analogue of $R^{2}$ with its $95 \%$ uncertainty interval (Gelman et al., 2019) as a measure of within-sample model fit. ${ }^{2}$

\section{Results}

Figure 1 shows the county-level predictor and outcome variables. Figure 2 shows the results of our analyses. In line with prior research (Graham et al., 2009; Kivikangas et al., 2021), county-level conservatism was associated with less concerns about fairness ( $\beta=-0.69,[-0.72$, $0.66])$ and greater concerns about loyalty $(\beta=0.73[0.71,0.75])$, authority $(\beta=0.53[0.51$, $0.55])$, and purity $(\beta=0.64[0.62,0.66])$ but was unrelated to concerns about care $(\beta=0.03[-$ $0.01,0.07])$. In line with our hypothesis, county-level pathogen prevalence was associated with greater concerns about loyalty $(\beta=0.13[0.11,0.15])$, authority $(\beta=0.16[0.14,0.18])$, and purity $(\beta=0.15[0.13,0.17])$ but was unrelated to concerns about fairness $(\beta=0.02[-0.01,0.05])$ and care $(\beta=0.01[-0.03,0.05])$. In summary, Study 1 provided the first evidence that geographic variation in pathogen prevalence is associated with regional differences in moral values. In particular, we found that county-level pathogen prevalence in the United States predicted county-level differences in the endorsement of the "binding" foundations, especially Authority and Purity, after controlling for their well-established association with political ideology.

\section{Study 2}

\footnotetext{
${ }^{2} R^{2}$ values only represent the non-spatial, fixed effects in each model.
} 
Pathogen prevalence can have regional influences on the development and persistence of norms and beliefs (Thornhill \& Fincher, 2014; Van Leeuwen et al., 2012). Our estimates of pathogen prevalence in Study 1 relied on recent prevalence of infectious diseases in the U.S., making it crucial to replicate that cross-region effect across cultures. Previous cross-cultural studies have also shown that moral systems differ across countries (Graham et al., 2011), and that variation in pathogen prevalence is often associated with cultural-psychological outcomes (Murray \& Schaller, 2010). Merging these two ideas, we postulate that cross-cultural variation in pathogen prevalence is associated with moral systems while controlling for how much those cultures are Western, Educated, Industrialized, Rich, Democratic (WEIRD) (Henrich, Heine, \& Norenzayan, 2010), homogeneous (Gelfand et al., 2011), or individualistic. Study 2 was designed to evaluate the unique effect of historical ecological pathogen prevalence on contemporary country-level moral values above and beyond cultures' WEIRDness, tightnesslooseness, and individualism as potential culture-level confounding variables.

\section{Methods}

Pathogen Prevalence. We used the historical pathogen prevalence data compiled by Murray and Schaller (2010), who used epidemiological atlases from the early $20^{\text {th }}$ century to gather prevalence data on nine infectious diseases (leishmanias, schistosomes, trypanosomes, leprosy, malaria, typhus, filariae, dengue, and tuberculosis) in 230 geopolitical regions worldwide. Since we have moral foundations data for 67 countries, we only used the historical pathogen prevalence for the same countries. All 67 countries were contained within Murray and Schaller's (2010) data set.

Moral Values. We used nation-level data based on responses to the MFQ provided by Atari et al. (2020). The data were collected from over 330,000 participants in 67 countries with 
at least 100 participants per country. We collected estimates of five moral foundations (Care, Fairness, Loyalty, Authority, and Purity). The median sample size in this data set was 439 participants per country.

Cultural Looseness. Cultural tightness (vs. looseness) taps into variance in norms, values, and behavior. Tight cultures typically have many strong norms and a low tolerance of deviant behaviors. Therefore, a tight culture facilitates homogeneity in traditions, norms, and behaviors. Looser cultures score higher on well-being, freedom of choice, tolerance for sexual deviations, and individualism, while being lower on traditionalism, population density, food deprivation, natural disasters, and institutional repression (Gelfand et al., 2011). Cultural looseness has been found to be associated with both moral values (Gelfand et al., 2011) and rate of infectious diseases (Gelfand et al., 2021) across cultures, so we controlled for cultural looseness in our analyses. We collected country-level indices of tightness-looseness from Uz (2015), where smaller indices indicate tighter cultures. Out of 67 countries in our sample, 51 had available data on looseness.

WEIRD cultural distance. A growing body of research suggests that populations around the globe vary substantially along several important psychological dimensions, and that people from societies characterized as WEIRD are particularly unusual (Henrich et al., 2010). Recently, Muthukrishna et al. (2020) developed and validated country-level cultural distance from the U.S., as a point of comparison. These "WEIRDness scores" are robust indicators of cultural distance, grounded in evolutionary theory. Out of 67 countries in our sample, 46 had data on WEIRD cultural distances.

Individualism. We controlled for individualism as it correlates with both pathogen prevalence in different countries (Fincher et al., 2008) and moral values (Hofstede, 2010). 
Country-level individualism indices were collected from Hofstede (2010). Individualism, in this framework, is defined as a preference for a loosely-knit social framework in which individuals are expected to take care of only themselves and their immediate families, whereas collectivism represents a preference for a tightly-knit framework in society in which individuals can expect their relatives or members of a particular ingroup to look after them in exchange for unquestioning loyalty (Hofstede, 2010). Except for one country (Afghanistan), we were able to secure individualism indices for all nations in our sample.

Analytic Procedure. Since the number of cultures we had obtained data from was small and countries are naturally geographically clustered, we used hierarchical linear models to examine the predictive effect of country-level pathogen prevalence on country-level moral values, while controlling for WEIRDness, cultural looseness, and individualism. We clustered countries in six geographical regions: Africa, Asia, Europe, North America, Oceania, and South America, yet Oceania was not included in the models as it only contains two countries (Australia and New Zealand) and these countries' looseness indices were missing. Our final sample included 34 countries (Argentina, Bulgaria, Canada, Chile, Egypt, Finland, France, Germany, Hungary, India, Indonesia, Iran, Italy, Japan, Mexico, Netherlands, Nigeria, Peru, Philippines, Poland, Romania, Russia, Serbia, Singapore, Slovenia, South Africa, South Korea, Spain, Sweden, Turkey, Ukraine, United Kingdom, United States, Vietnam) grouped in five regions.

\section{Results}

The scatter plots of the relationships between pathogen prevalence and moral values across 67 countries with complete data are shown in Figure 3. After controlling for WEIRDness, cultural looseness, and individualism, multilevel models suggested that pathogen prevalence, 
across 34 countries with complete data on all variables, was not associated with Care $(B=0.04$, $S E=0.06, p=.451)$ or Fairness $(B=-0.01, S E=0.06, p=.856)$. Loyalty was negligibly positively associated with pathogen prevalence $(B=0.17, S E=0.07, p=.021)$. However, there was compelling evidence that country-level pathogen prevalence was associated with Authority $(B=0.29, S D=0.09, p=.003)$ and Purity $(B=0.27, S D=0.09, p=.005)$, over and above WEIRDness, cultural looseness, and individualism.

Figure 3

Cross-country relationships between pathogen prevalence and moral values. 

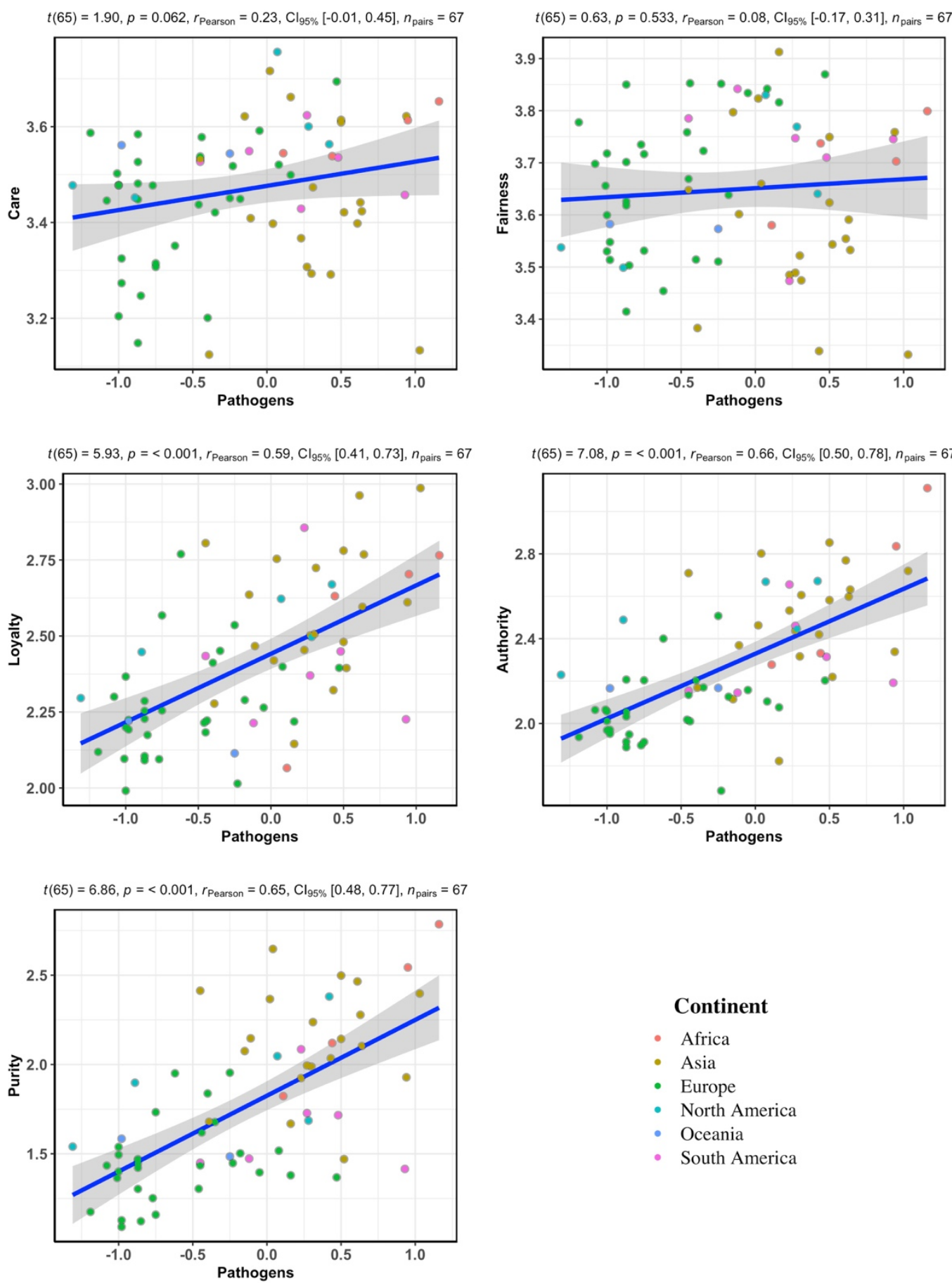

Endorsement of Purity and historical exposure to pathogens across 67 countries are shown in Figure 3 (distributions of other moral values are presented in Supplementary Materials). As shown, historical pathogen prevalence (i.e., aggregation of prevalence of 
infectious diseases in the past century) is associated with contemporary Authority and Purity values across countries (see Figure 3), above and beyond countries' WEIRDness, looseness, and individualism. Complete models are presented in Table 2.

Figure 4

Historical presence of infectious diseases and contemporary Purity values around the world.

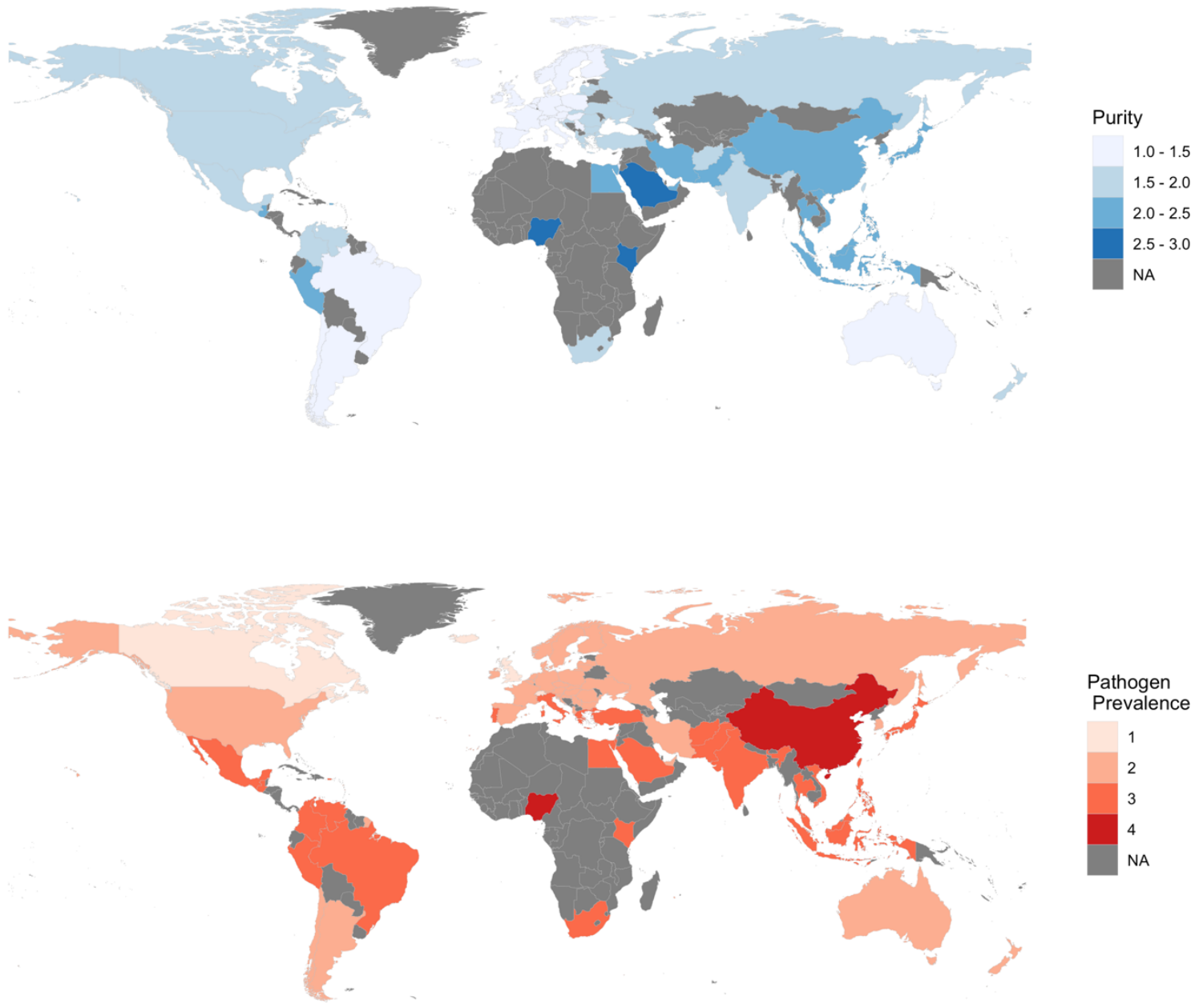


Table 2

Five multilevel models predicting moral values across cultures

\begin{tabular}{lccccc} 
& \multicolumn{5}{c}{ Dependent variable: } \\
\cline { 2 - 6 } & Care & Fairness & Loyalty & Authority & Purity \\
& $(1)$ & $(2)$ & $(3)$ & $(4)$ & $(5)$ \\
\hline Pathogen Prevalence & 0.042 & -0.011 & $0.169^{*}$ & $0.288^{* * *}$ & $0.265^{* *}$ \\
& $(0.055)$ & $(0.060)$ & $(0.069)$ & $(0.086)$ & $(0.088)$ \\
Cultural Looseness & -0.002 & 0.034 & 0.010 & 0.006 & -0.080 \\
& $(0.035)$ & $(0.038)$ & $(0.044)$ & $(0.053)$ & $(0.051)$ \\
Individualism & 0.001 & -0.0003 & -0.004 & -0.002 & -0.004 \\
WEIRDness Distance & $(0.002)$ & $(0.002)$ & $(0.002)$ & $(0.002)$ & $(0.002)$ \\
& 0.084 & 0.648 & 1.085 & 0.518 & 0.693 \\
Constant & $(0.846)$ & $(0.913)$ & $(1.057)$ & $(1.268)$ & $(1.214)$ \\
& $3.437^{* * *}$ & $3.610^{* * *}$ & $2.464^{* * *}$ & $2.343^{* * *}$ & $1.914^{* * *}$ \\
\hline \multirow{2}{*}{ Observations } & $(0.115)$ & $(0.124)$ & $(0.143)$ & $(0.175)$ & $(0.178)$ \\
Log Likelihood & 34 & 34 & 34 & 34 & 34 \\
Akaike Inf. Crit. & 5.917 & 3.624 & -0.559 & -6.106 & -5.713 \\
Bayesian Inf. Crit. & 2.167 & 6.752 & 15.119 & 26.211 & 25.426 \\
\hline & 12.851 & 17.436 & 25.803 & 36.896 & 36.111 \\
\hline
\end{tabular}

Note. ${ }^{*} p<0.05 ;{ }^{* *} p<0.01 ;{ }^{* * *} p<0.001$

Taking a historical-evolutionary perspective, strict rules and social hierarchies dominated by designated authorities or prestigious individuals have facilitated group coordination during collective threats such as pathogen outbreaks. Of note, our results show no compelling evidence that Care, Fairness, or Loyalty can be predicted by historical pathogen prevalence, especially when clustering is taken into account and potential confounding variables are adjusted for. This 
cross-cultural study replicates the Purity effect found in Study 1 (in U.S. counties), but also highlights the role of historical pathogen prevalence on Authority values (e.g., obedience, respectfulness, hierarchy adherence) across cultures. Purity and Authority values might be two equally important mechanisms to bring order to cultures stressed by high prevalence of infectious diseases, one by strengthening social hierarchies and order-restoring authorities, and the other by reinforcing personal hygiene, inflicting moral/social costs on promiscuity and uncleanliness. We do note here that correlational studies of aggregated country-level data are not optimal for testing hypotheses about psychological processes (e.g., Bromham et al., 2018). Hence, these results should be interpreted in a complementary manner with Study 1, as well as the following studies in which we aim to unpack some of the historical and psychological processes underlying the relationship between pathogen prevalence and moral systems.

\section{Study 3}

In this study, we examine the semantic association between pathogen-related words and moral foundations using word embeddings - pre-trained models for distributed representation of word meaning induced from patterns of word co-occurrences in a wide-coverage corpus of text. In word-embedding models, each word is represented by a numeric vector such that the geometry of the vectors captures semantic relations between the words. As such, if two concepts are semantically close to one another, they should co-occur in similar linguistic contexts, resulting in their embeddings being closer to one another in the semantic space (Collobert et al., 2011; Garten et al., 2018). Since traces of psychological processes are manifested in language (Jackson et al., 2021), psychologically related concepts should co-occur in similar linguistic contexts (e.g., Garg et al., 2018). Therefore, we expect that pathogen-related concepts should semantically be closer to the specific moral foundations which are psychologically more related 
to them. Specifically, we use the word-embedding model of semantic representations to examine the semantic similarity between pathogen-related words and words representing moral foundations in English. In order to make sure that these associations are not idiosyncratic features of English, we replicate this analysis in four other languages — Spanish, Farsi, Japanese, and Hebrew — which represent a diverse collection of language families (Romance Indo-European, Indo-Iranian, Japonic, and Northwest Semitic, respectively).

\section{Methods}

As discussed above, word embeddings are a popular natural language processing method that represents each word by a vector, such that geometric relatedness - e.g., cosine similarity between vectors - captures clusters of lexical semantic meaning and common usage patterns. These similarities approximate both the intrinsic linguistic relationships among words, such as the relationship among tenses for a given lemma, as well as their usage across large text corpora. The "FastText" algorithm (Bojanowski et al., 2017) generates word vectors using subword information in the same style as the popular "Word2vec" skipgram algorithm (Mikolov et al., 2013), and has been used to generate word embedding sets for a large host of languages (Grave et al., 2018). We used 300-dimension FastText vectors trained on the "Common Crawl" corpora $^{3}$, for each language in our analyses.

We measure the moral loading of pathogen-related words by computing the cosine similarity between each pair of moral- and pathogen-related words. Moral seed words were taken from Garten et al. (2018), and a set of ten pathogen-related words was generated for this work: “virus”, “flu”, “disease”, “infection”, “sickness”, “germ”, “contagion”, “illness" (translated to Spanish, Farsi, Japanese, and Hebrew by native speakers who were blind to the

\footnotetext{
${ }^{3}$ https://commoncrawl.org/
} 
purpose of the study; see Supplementary Materials). The cosine similarity for all pairs of moral and pathogen-related words are calculated to analyze the semantic similarity between moral foundations and pathogens in natural language (see Garten et al., 2018). To examine the similarities between moral foundations and pathogen-related words, a robust one-way Analysis of Variance (ANOVA) was conducted with $p$-values adjusted for False Discovery Rates (FDR) and pairwise comparisons based on Yuen's trimmed means test. As a measure of effect size, we relied on "explanatory measure of effect size" $\xi$ which does not require equal variances and can be generalized to multiple group settings (Wilcox \& Tian, 2011).

\section{Results}

Similarity results revealed that Purity and Care words were closest to the pathogenrelated words in English (Purity and Care were not different from one another in their similarity to pathogen-related words, $p=.643$ ). The robust one-way ANOVA showed that differences between the five similarity distributions were significantly different $(F(4,127.41)=14.23, \xi=$ $0.45,95 \% \mathrm{CI}=[0.34,0.56], p<.001)$. Post-hoc pairwise tests indicated that Purity was semantically closer to infectious diseases than Authority $(p<.001)$, Loyalty $(p<.001)$, and Fairness $(p=.011)$. Next, Care was shown to be more related to infectious diseases words than were Fairness $(p<.001)$, Loyalty $(p<.001)$, and Authority $(p<.001)$. Similarities of Fairness, Loyalty, and Authority to pathogen words were not different from each other ( $p$ s $>.643)$. In sum, words related to infectious diseases appear substantially more often in similar contexts with Purity and Care words compared with Fairness, Loyalty, and Authority. We also replicated these patterns in $\operatorname{Spanish}(F(4,109.57)=2.85, \xi=0.24,95 \% \mathrm{CI}=[0.09,0.34], p=.027)$, Farsi $(F(4$, $123.22)=2.58, \xi=0.19,95 \% \mathrm{CI}=[0.05,0.27], p=.040)$, Japanese $(F(4,112.03)=6.18, \xi=$ $0.30,95 \% \mathrm{CI}=[0.17,0.38], p<.001)$, and Hebrew $(F(4,93.37)=7.63, \xi=0.41,95 \% \mathrm{CI}=$ 
$[0.28,0.51], p<.001$ ), but the effect sizes were smaller in other languages (see Supplementary Materials for details). These findings suggest that across five languages originating from different cultures and language families, pathogen-related words co-occur with Purity and Care more frequently than other moral concerns, highlighting that Purity and Care concerns are associated with cognitive processes (e.g., passing moral judgments about suffering or cleanliness) underlying representations of pathogen-related concepts.

\section{Study 4}

The previous studies are community-level analyses, investigating the relationship between ecological pathogen prevalence and region-level moral concerns, in addition to linguistic association of pathogen and morality-related words. Indeed, macro-level analyses of communities cannot be generalized to individual-level processes as that risks committing the ecological fallacy. Given that group and individual levels of analysis often do not yield isomorphic results (Oyserman et al., 2002), deeper insights can be gained by simultaneously analyzing the independent effect of group-level and individual-level processes. In Study 4, we aim to examine how individual differences in moral concerns are related to pathogen avoidance behaviors. This study further clarifies individual-level moral psychological processes in avoiding infectious diseases. Specifically, we examine the relationship between moral foundations and pathogen avoidance behaviors while controlling for political orientation and religiosity in a cross-sectional design using a stratified sample from the United States.

\section{Methods}

Participants. We aimed to recruit a sample of 500 participants to detect small correlational effects $(\rho=.15)$ with high power $(95 \%)$. We recruited a stratified national U.S. sample from Qualtrics Panels, balanced with respect to age, gender, and political affiliation. 
Participants $(N=513)$ were almost half $(51.3 \%)$ female and predominantly $(63 \%)$ White American. In terms of age, $11.1 \%$ were in the $18-24$ range, $18.1 \%$ were in the $25-34$ range, $16.8 \%$ were in the $35-44$ range, $18.9 \%$ were in the $45-54$ range, $17.0 \%$ were in the $55-64$ range, and $18.1 \%$ were 65 years old or older. In terms of political affiliation, 263 participants (51.3\%) identified as a Democrat while the rest identified as a Republican.

Design and Materials. Our Institutional Review Board (IRB) approved this study (UP19-00395). To measure the constructs of interest, participants completed a set of measures including the short Moral Foundations Questionnaire (MFQ-20; Graham et al., 2011) (Cronbach's $\alpha \mathrm{s}=.62-.73$ ) and a 2-scenario measure of pathogen avoidance behavior (Cronbach's $\alpha=.59,95 \% \mathrm{CI}=[.52, .66])$ along with their demographic details. We collected data in this study in March 2019. These two hypothetical scenarios, designed for this study, were "Imagine that a few months ago you booked a flight to a beautiful country abroad for a vacation. One or two days before your flight you find that there has been an outbreak of a dangerous infectious disease in that country, but the local authorities have controlled the situation. How likely is it for you to go on this vacation?" and "Some infectious diseases cannot be transmitted through skin contact unless one's skin has small bloody cuts. How likely is it for you to sit next to a person with such a disease on the bus?'. Both questions were rated on a 7-point Likert-type scale ranging from 1 (Extremely unlikely) to 7 (Extremely likely). In this cross-sectional observational study, all items and measures were counterbalanced. We used linear regression models to account for gender, and political ideology, along with moral foundations to predict pathogen avoidance behaviors.

\section{Results}


In a linear model controlling for gender and political ideology, Purity was significantly positively associated with pathogen avoidance behaviors $(\beta=0.25, S E=0.09, p$ $=.006)$. Fairness was also shown to have a negative association with pathogen avoidance $(\beta$ $=-0.34, S E=0.13, p=.010)$. Other moral values, political ideology, and gender had nonsignificant effects $(p \mathrm{~s}>.07)$. These results highlight the individual-level processes between pathogen avoidance behaviors and moral Purity. These patterns are consistent with our cross-cultural and linguistic analyses (Studies 2 and 3), implicating Purity concerns in relation to perceptions of infectious diseases at individual level.

\section{Study 5}

When people feel more in immediate danger of infectious diseases they report lower levels of sociability (i.e., decreased interest in frequent contact with others) and produce more avoidant motor responses (Mortensen et al., 2010). Research also suggests that moral vigilance is increased when people are experimentally exposed to salience of infectious disease threats (Murray et al., 2019). In order to complement our previous analyses using an MFT framework, in the current study we use an experimental design and expose participants to visual cues of pathogens and assess their moral judgments compared with a control group exposed to neutral stimuli.

\section{Methods}

Participants. Based on prior work and a power analysis to detect a small-to-moderate effect size $(r=.20)$ at $p=.05$ and $90 \%$ power, we aimed to collect 320 participants. We collected data in this study in April 2019. We recruited 334 participants from Amazon Mechanical Turk. After removing the participants who failed an attention check, a total of 316 participants remained in the sample (130 male, 182 female, 4 other). Most participants were White 
Americans $(n=247)$, followed by Black Americans $(n=41)$. The mean age was 32.6 years $(S D$ $=11.3$ years $)$.

Design and Materials. Culpepper et al. (2018) identified main domains of pathogenrelated disgust and generated a novel visual stimulus set of 20 images depicting scenes of highly salient pathogen risk, along with a paired control set (20 images) that are visually comparable but lack the pathogen cues. Our Institutional Review Board (IRB) approved this experimental study (UP-18-00712). Participants were randomly assigned to the experimental (vs. control) group, receiving experimental (vs. control) stimuli. Participants in the experimental (vs. control) group were given three pathogen images (vs. non-pathogen counterparts) and were asked to look at them for a few seconds and then answer questions about these images. As a manipulation check, we asked participants to rate how "pleasant" each scene was $(1=$ "Not at all pleasant", $5=$ “Extremely pleasant”). Right after being exposed to pathogen (vs. non-pathogen) cues, participants completed the 30-item MFQ (Graham et al., 2011) (Cronbach's $\alpha=.62-.78$ ) along with their demographic details. Participants also completed the Short-Form of the Positive and Negative Affect Schedule (PANAS; Thompson, 2007) after completing the MFQ to measure their momentary negative affect (Cronbach's $\alpha=.81$ ) after being exposed to experimental (vs. control) stimuli. We controlled for negative affect to account for the role of negative affect that might be evoked by pathogen stimuli in moral judgments.

\section{Results}

First, we compared the "pleasantness" ratings to make sure that our experimental manipulation worked. The experimental group $(M=0.18, S D=0.41)$ rated the images significantly less pleasing compared to the control group $(M=1.09, S D=0.65), t=14.63$, Welch-corrected $d f=256.45, p<.001$, Cohen's $d=1.65)$. We ran regression analyses to predict 
scores on moral foundations by condition (experimental vs. control), while statistically controlling for gender, age, and negative affect. Results suggested that being exposed to pathogen cues does not predict Care $(B=0.18, S E=0.49, p=.723)$, Fairness $(B=-0.30, S E=$ $0.48, p=.527)$, Loyalty $(B=0.25, S E=0.65, p=.705)$, or Authority $(B=0.50, S E=0.60, p=$ .404). However, participants in the experimental (vs. control) condition scored an average of $1.54(S E=0.74, p=.038)$ points higher on the Purity questionnaire items than participants in the control condition. Therefore, in experimental settings, visual cues to pathogens can influence Purity judgments, but not moral judgments in other domains. This effect is independent of how much negative affect people experience when exposed to pathogenic visual stimuli. Domainspecific effects of pathogen cues highlight the adaptive benefits of Purity in immediate pathogenrich environments. In other words, Purity is a context-sensitive, environmentally-plastic, pathogen-neutralizing suite of moral psychological mechanisms that function to avoid pathogen contact.

\section{Study 6}

Our community-level analyses were observational, hence no strong claims can be made with regard to the direction of the effect in the relationship between Purity and pathogen prevalence. Also, our data were contemporary, masking historical precedence of these variables over one another. For example, it is not clear whether particularly low levels of Purity (and other moral values) precede higher levels of pathogen prevalence or, alternatively, high levels of pathogen prevalence cause moral values to change in subsequent years. Here, we explore this question by combining historical data on infectious diseases in the U.S. as well as historical language data on moral values. Indeed, cultural and societal changes can be captured using linguistic analysis of large historical corpora of books and texts produced in recent history (Atari 
\& Dehghani, 2021; Greenfield, 2013). Specifically, we rely on moral language used in published books in the $20^{\text {th }}$ century (Michel et al., 2011), and historical prevalence of infectious diseases in the U.S. to examine the temporal link between infectious diseases and severity of moral language, while controlling for fluctuations in strength of social norms (cultural looseness) as a potential confounder.

\section{Methods}

Pathogen Prevalence. Data were adapted from Grossmann and Varnum (2015), who reported 9 of the most frequent infectious diseases reported by the historical records of the CDC. This data set included tuberculosis, syphilis, gonorrhea, malaria, typhoid and paratyphoid fever, diphtheria, pertussis, measles, and poliomyelitis. The data included prevalence rates from 1912 through 2012.

Moral Language Usage. In order to collect yearly usage of moral language, we relied on Google Ngram data, which is the largest available time-stamped corpus through 2008 (Michel et al., 2011). The current data ranged from 1900 to 2008. The corpus consists of words and phrases (i.e., n-grams) and their usage frequency over time. We relied on the Moral Foundations Dictionary (MFD; Graham et al., 2009) and collected the frequency for each word in the dictionary from 1900-2008.

Cultural Looseness. Cultural looseness was controlled for, as it correlates with both moral values and existence of pathogenic threats (Gelfand et al., 2011; Jackson et al., 2020). We used Jackson et al.'s (2019) estimates of cultural looseness in recent history. These authors used Google Ngram data, published between the years 1800 and 2000 and reported standardized frequency of loose (e.g., "Allow”, "Freedom”, “Autonomy”) and tight (e.g., "Restrain”, "Prevent", "Adhere") words. 
Analytic Procedure. Prior to our analyses, we de-trended our time-series vectors by regressing out monotonic effect of time, general moral language, and cultural looseness. Then we subjected each time-series vector to augmented Dickey-Fuller root tests, to evaluate whether a time-series vector has an underlying trend that renders it non-stationary. We next used standardized vectors to examine the correlation between moral language and pathogen prevalence, and used cross-correlations to test whether moral norms preceded decrease in the prevalence of infectious diseases. Finally, we conducted additional tests of Granger causality to assess the relationship between moral norms and pathogen prevalence (as well as the reverse relationships) in the $20^{\text {th }}$ century. Granger tests of causality are more conservative than crosscorrelations as they evaluate whether one time-series variable is predicting changes to another time-series variable above and beyond values of the outcome (Seth et al., 2015).

\section{Results}

Cross-correlations (the correlations between two variables at different time lags) are visualized in Figure 5: negative lags (left side of the dashed red line) indicate that pathogen prevalence precedes changes in moral language usage, while positive lags (right side of the dashed red line) indicate that moral language usage precedes pathogens. As can be seen, pathogen prevalence predicted immediate slight increases in Care and Loyalty. However, the largest effect was observed for Purity. Cross-correlations between Purity language and pathogen prevalence suggested that not only do they significantly co-occur in the same years, but pathogen prevalence seems to drop immediately in subsequent years of high Purity norms in the United States (see Figure 5), supporting the prediction that Purity functions to reduce communicable diseases. We further investigated the direction of these relationships in Granger causality tests (Table 3). We found strong evidence, consistent with cross-correlations, that Purity immediately 
"Granger caused" pathogens to drop (1-year lag), and the effect held for the 5-year lag too. Of note, high Care values seem to also precede higher rates of infectious diseases, but the effect did not hold for the 5-year lag. In the reverse models in Table 3 (pathogens "Granger causing" moral foundations), we did not find evidence suggesting that pathogen prevalence can have immediate 1- or 5-year effects on moral foundations except for a small effect on Care values with a 5-year lag.

Figure 5

Cross-correlations between pathogen prevalence and indicators of moral language. Correlations outside the dashed blue horizontal lines are significant at $\alpha=.01$. Negative lags (left side of the dashed red vertical line) indicate that shifts in pathogen prevalence led to shifts in moral language, whereas positive lags (right side of the dashed red vertical line) indicate that shifts in pathogen prevalence followed shifts in moral language.
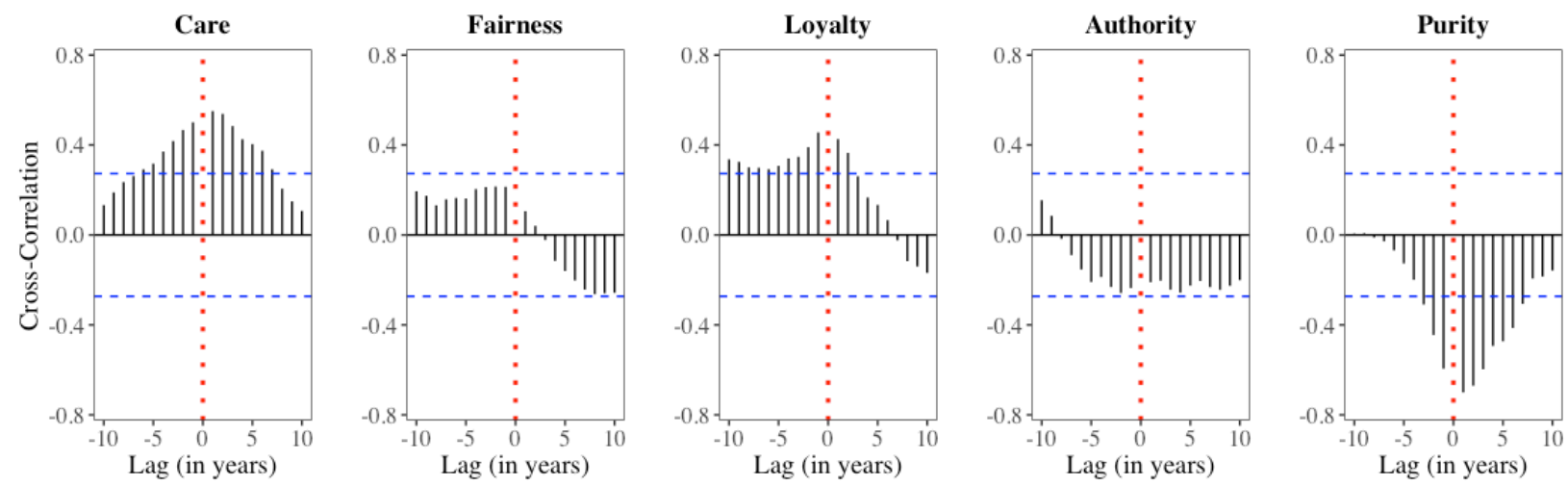

Table 3

Granger Causality Test Results with 1-year-lagged and 5-year-lagged Models

\begin{tabular}{lll} 
Granger Causality Model & 1-year lag & 5-year lag \\
\hline Pathogen $\rightarrow$ Care & $\mathrm{F}(1,86)=0.14$ & $\mathrm{~F}(5,78)=4.06^{* *}$
\end{tabular}




\begin{tabular}{lll} 
Pathogen $\rightarrow$ Fairness & $\mathrm{F}(1,86)=1.71$ & $\mathrm{~F}(5,78)=0.91$ \\
Pathogen $\rightarrow$ Loyalty & $\mathrm{F}(1,86)=0.31$ & $\mathrm{~F}(5,78)=2.84$ \\
Pathogen $\rightarrow$ Authority & $\mathrm{F}(1,86)=0.96$ & $\mathrm{~F}(5,78)=2.97$ \\
Pathogen $\rightarrow$ Purity & $\mathrm{F}(1,86)=2.36$ & $\mathrm{~F}(5,78)=0.49$ \\
\hline Care $\rightarrow$ Pathogen & $\mathrm{F}(1,86)=8.91 * *$ & $\mathrm{~F}(5,78)=1.86$ \\
Fairness $\rightarrow$ Pathogen & $\mathrm{F}(1,86)=0.04$ & $\mathrm{~F}(5,78)=1.71$ \\
Loyalty $\rightarrow$ Pathogen & $\mathrm{F}(1,86)=2.47$ & $\mathrm{~F}(5,78)=1.67$ \\
Authority $\rightarrow$ Pathogen & $\mathrm{F}(1,86)=0.79$ & $\mathrm{~F}(5,78)=1.11$ \\
Purity $\rightarrow$ Pathogen & $\mathrm{F}(1,86)=20.11^{* * *}$ & $\mathrm{~F}(5,78)=3.44 * *$ \\
\hline & & \\
* ${ }^{* * *} p<.001$ & &
\end{tabular}

In this study, the results indicate that historical prevalence of pathogens highly co-occurs with moral values associated with group cohesion, specifically Purity values (indexed by more frequent usage of Purity words), after controlling for other types of moral language and historical estimates of cultural looseness. Cross-correlations and Granger causality tests revealed a pattern where higher levels of Purity values co-occur with, and immediately causes, lowered levels of pathogen prevalence in the United States in the $20^{\text {th }}$ century. Therefore, it seems that psychological mechanisms associated with Purity can act as a unique pathogen-neutralizing mechanism (possibly through social and physical distancing; Dehghani et al., 2016), lowering subsequent levels of infectious diseases. The finding that lower Purity values are historically related to more infectious diseases can be explained by the fact that low Purity values bring about higher unprotected sexual encounters, higher physical proximity-seeking, and lesser aversion toward disgusting things, which in turn can exacerbate the contagion of infectious diseases such as sexually transmitted infections.

\section{General Discussion}


A single pandemic caused by an infectious disease can kill tens of millions of people worldwide and make hundreds of millions ill (see Ackerman et al., 2021). In addition to biological systems to fight off pathogens, humans have developed behavioral systems to avoid pathogenic agents before bodily contact, or to stay away from highly contagious environments. Here, in a series of studies, we demonstrate that across hyperlocal geographical regions (Study 1), cultures (Study 2), linguistic contexts (Study 3), individuals (Study 4), and experimental conditions (Study 5), presence of pathogens is consistently linked to moral Purity systems. Indeed, Purity values may function to neutralize infectious diseases, possibly through lowered sexual contact, hygienic practices, avoidance of unfamiliar foods and/or persons who may be perceived to be associated with the origin of the disease. Finally, our historical analysis in Study 6 demonstrated that high moral Purity norms in the $20^{\text {th }}$ century in the U.S. is followed by a decrease in infectious diseases.

The unique relationship between pathogen salience and Purity highlights the evolutionarily crucial role of moral Purity in survival of individuals and flourishing of groups across historical periods and geographic regions in the face of recurring increase in the occurrence of infectious diseases. At the county and national levels, Purity values might be more successfully transmitted and sustained within pathogen-rich ecologies if such norms lead to reduced contact with pathogenic agents (Murray \& Schaller, 2016). Prior psychological work indicates that pathogens can result in the cultural evolution of prophylactic norms and rituals (Tanaka et al., 2002; Tybur et al., 2016) embedded in Purity value systems, possibly through lowering the likelihood of unsafe sex, avoidance of unhygienic food, and shunning pathogenrich places. In addition, Purity has been shown to have a particularly unique effect in promoting within-coalition alliances, an effect referred to as "purity homophily" (Dehghani et al., 2016), 
which in turn can provide ingroup coalitions in times of disease outbreaks especially in pathogen-dense ecologies (Navarrete \& Fessler, 2006). Indeed, in ancestral environments, interaction with ingroup members may have posed less risk of disease transmission than interaction with an outgroup member, since individuals possessed antibodies to many of the pathogens present in their own community, in contrast to those circulating among people coming from other regions.

At the individual level, people in high avoidance of infectious diseases might find Purity rituals (e.g., refraining oneself from sexual intercourse with an unknown individual) appealing for a number of reasons. First, "pure" sexual practices often expose individuals to substantially fewer sexually transmitted infections (Bauch \& McElreath, 2016). Second, Purity practices facilitate safer and more traditional food preparation techniques which often include ingredients with antimicrobial properties (Billing \& Sherman, 1998). Third, hygiene-related Purity rituals (e.g., burial rituals) can coordinate behaviors to limit pathogen transmission. We argue that each of these lower-order mechanisms have intrapersonal (e.g., refraining oneself from contact with pathogens) and interpersonal (e.g., penalizing others' contact with pathogens) components. While pathogenic threats can be detrimental to the survival of an individual or group, their extremely low rates can have harmful effects on our health. The Hygiene Hypothesis, for example, suggests that humans have evolved in environments where childhood exposure to infectious agents was high. In industrialized settings, immunological diseases become common due to the lack of this exposure (e.g., Apicella \& Barrett, 2016; Yazdanbakhsh et al., 2002). Care values, as implicated in our linguistic, temporal, and county-level analyses, might be specific to the suffering and mortality accompanied by severe infectious disease (see Studies 1, 2, and 3). Particularly, it could be the case that pathogen outbreaks may lead to temporary, 
subsequent increases in the tendency to care for afflicted individuals. In addition, individuals typically talk about harms, sufferings, and deaths when speaking about infectious disease, which explains our linguistic findings in Study 3. Authority values were also linked to country-level pathogen prevalence in our cross-cultural analysis, almost as strongly as Purity values (Van Leeuwen et al., 2012). This finding can be understood within cultural evolution frameworks which combine familial transmission with selective learning from locally prestigious individuals. In high-pathogen ecologies, individuals are safer as long as they are under family ties and abide by powerful prestigious authorities (who potentially have more social power and/or more knowledge), whereas such an effect may not hold for historically low-pathogen, WEIRD cultures such as the U.S. or Canada. These results, along with little to no evidence regarding the relationship between pathogen prevalence and ingroup loyalty, are wholly consistent with previous findings in the cultural evolution literature (Hruschka \& Henrich, 2013). Lack of strong links between pathogen prevalence, Fairness, and Loyalty across time and space may also suggest that Fairness and Loyalty are less pathogen-plastic, i.e., less dependent upon the ecological factor of pathogen prevalence across time and place. Purity, on the other hand, appears to be highly functionally flexible with respect to pathogens in the environment, i.e., sensitive to costs and benefits of pathogen avoidance in the environment. The results of these studies broadly support the theory that purity-based moral systems have their functional roots in the survival and reproduction of individuals, and that Purity norms are culturally learned to counter the collective threat of pathogen prevalence (see Boyd et al., 2011).

While we highlight the specialized role of Purity in response to pathogenic threats, we also warn against its exclusive nature in contemporary intergroup dynamics. That is, Purity may function as a double-edged sword in fending off pathogenic threats such as COVID-19: on the 
advantageous side, Purity values encourage social distancing through perceived severity of the threat; and on the socially destructive side, they can lead to antipathic sentiment toward outgroup members (e.g., Hoover et al., 2021), especially those who are perceived to be somehow associated with the origin of the outbreak (i.e., the Chinese in the case of COVID-19) (Faulkner et al., 2004; see Misra et al., 2020). Purity values can predispose people to negatively evaluate outgroup members who are perceived to be potential carriers of pathogens, subsequently justifying prejudicial or exclusive behaviors (e.g., hate crimes against outgroup members) or policies (e.g., imposing travel bans or deportations). In addition, recent research suggests that regional variation in Purity across U.S. counties is reliably associated with lower vaccination rates (Karimi-Malekabadi et al., 2021), which can be thought of as an ironic effect since Purity values may have culturally evolved to guard people against diseases, but the same values in contemporary settings seem to discourage vaccination, one of the most effective ways to combat communicable diseases at individual and population levels (Amin et al., 2017). This ironic effect may be attributable to the contemporary pandemic mismatch: while historically infectious diseases have been easily detectable (e.g., open sores), the cues to COVID-19 are limited due to asymptomatic and presymptomatic transmission of the disease (Ackerman et al., 2021), coupled with some politicians' rhetoric downplaying the threat of the disease (Calvillo et al., 2020).

By integrating insights from psychology, anthropology, and behavioral ecology paired with methodologies from multiple disciplines, this research illuminates a unified way to better understand and explain historical and contemporary variation in moral Purity (as well as other moral foundations) in response to infectious diseases. These basic moral systems may in turn predict cultural outcomes, such as religious, economic, political institutions, hence linking ecological factors to psychological outcomes, and eventually large-scale institutions that regulate 
and oversee social behaviors. This set of studies suggests that Purity consistently functions as a mechanism to allay pathogenic threats across time and space at different levels of analysis, further shedding light on historical-evolutionary architecture and socio-ecological plasticity of human moral systems. 


\section{References}

Ackerman, J. M., Tybur, J. M., \& Blackwell, A. D. (2021). What role does pathogen-avoidance psychology play in pandemics?. Trends in Cognitive Sciences, 25(3), 177-186.

Alexander, R. M. (2019). The Spanish flu and the sanitary dictatorship: Mexico's response to the 1918 influenza pandemic. The Americas, 76, 443-465.

Amin, A. B., Bednarczyk, R. A., Ray, C. E., Melchiori, K. J., Graham, J., Huntsinger, J. R., \& Omer, S. B. (2017). Association of moral values with vaccine hesitancy. Nature Human Behaviour, 1(12), 873-880.

Apicella, C. L., \& Barrett, H. C. (2016). Cross-cultural evolutionary psychology. Current Opinion in Psychology, 7, 92-97.

Atari, M., \& Dehghani, M. (2021). Language analysis in moral psychology. In M. Dehghani \& R. Boyd (Eds.), Handbook of language analysis in psychology (pp. 207-228). Guilford.

Atari, M., Lai, M. H. C., \& Dehghani, M. (2020). Sex differences in moral judgements across 67 countries. Proceedings of the Royal Society B, 20201201.

Bastian, B., Vauclair, C.-M., Loughnan, S., Bain, P., Ashokkumar, A., Becker, M., . . Swann, W. B. (2019). Explaining illness with evil: pathogen prevalence fosters moral vitalism. Proceedings of the Royal Society B: Biological Sciences, 286, 20191576.

Bauch, C. T., \& McElreath, R. (2016). Disease dynamics and costly punishment can foster socially imposed monogamy. Nature Communications, 7, 11219.

Besag, J. (1974). Spatial interaction and the statistical analysis of lattice systems. Journal of the Royal Statistical Society: Series B (Methodological), 36(2), 192-225.

Billing, J., \& Sherman, P. W. (1998). Antimicrobial functions of spices: why some like it hot. The Quarterly Review of Biology, 73, 3-49. 
Bojanowski, P., Grave, E., Joulin, A., \& Mikolov, T. (2017). Enriching word vectors with subword information. Transactions of the Association for Computational Linguistics, 5, $135-146$.

Boyd, R., Richerson, P. J., \& Henrich, J. (2011). The cultural niche: Why social learning is essential for human adaptation. Proceedings of the National Academy of Sciences, 108, 10918-10925.

Bromham, L., Hua, X., Cardillo, M., Schneemann, H., \& Greenhill, S.J. (2018). Parasites and politics: why cross-cultural studies must control for relatedness, proximity and covariation. Royal Society Open Science, 5(8), 181100.

Bürkner, P.-C. (2017). Brms: An R package for Bayesian multilevel models using Stan. Journal of Statistical Software, 80 (1), 1-28.

Bürkner, P.-C. (2018). Advanced Bayesian multilevel modeling with the R package brms. The $R$ Journal, 10(1), 395-411.

Calvillo, D. P., Ross, B. J., Garcia, R. J., Smelter, T. J., \& Rutchick, A. M. (2020). Political ideology predicts perceptions of the threat of COVID-19 (and susceptibility to fake news about it). Social Psychological and Personality Science, 11(8), 1119-1128.

Collobert, R., Weston, J., Bottou, L., Karlen, M., Kavukcuoglu, K., \& Kuksa, P. (2011). Natural language processing (almost) from scratch. Journal of Machine Learning Research, 12, $2493-2537$.

Culpepper, P. D., Havlíček, J., Leongómez, J. D., \& Roberts, S. C. (2018). Visually activating pathogen disgust: A new instrument for studying the behavioural immune system. Frontiers in Psychology, 9, 1397. 
Curtis, V., De Barra, M., \& Aunger, R. (2011). Disgust as an adaptive system for disease avoidance behaviour. Philosophical Transactions of the Royal Society B: Biological Sciences, 366, 389-401.

Damasio, A. (2019). The strange order of things: Life, feeling, and the making of cultures. Vintage.

Damasio, A., \& Carvalho, G. B. (2013). The nature of feelings: Evolutionary and neurobiological origins. Nature Reviews Neuroscience, 14, 143-152.

Dehghani, M., Johnson, K., Hoover, J., Sagi, E., Garten, J., Parmar, N. J., . . Graham, J. (2016). Purity homophily in social networks. Journal of Experimental Psychology: General, 145, $366-375$.

Faulkner, J., Schaller, M., Park, J. H., \& Duncan, L. A. (2004). Evolved disease-avoidance mechanisms and contemporary xenophobic attitudes. Group Processes \& Intergroup Relations, 7(4), 333-353.

Fincher, C. L., \& Thornhill, R. (2012). Parasite-stress promotes in-group assortative sociality: The cases of strong family ties and heightened religiosity. Behavioral and Brain Sciences, $35,61-79$.

Fincher, C. L., Thornhill, R., Murray, D. R., \& Schaller, M. (2008). Pathogen prevalence predicts human cross-cultural variability in individualism/collectivism. Proceedings of the Royal Society B: Biological Sciences, 275, 1279-1285.

Garg, N., Schiebinger, L., Jurafsky, D., \& Zou, J. (2018). Word embeddings quantify 100 years of gender and ethnic stereotypes. Proceedings of the National Academy of Sciences, 115, E3635-E3644. 
Garten, J., Hoover, J., Johnson, K. M., Boghrati, R., Iskiwitch, C., \& Dehghani, M. (2018). Dictionaries and distributions: Combining expert knowledge and large scale textual data content analysis. Behavior Research Methods, 50, 344-361.

Gelfand, M. J., Jackson, J. C., Pan, X., Nau, D., Pieper, D., Denison, E., ... \& Wang, M. (2021). The relationship between cultural tightness-looseness and COVID-19 cases and deaths: A global analysis. The Lancet Planetary Health, 5(3), e135-e144.

Gelfand, M., Raver, J. L., Nishii, L., Leslie, L. M., Lun, J., Lim, B. C., . . Yamaguchi, S. (2011). Differences between tight and loose cultures: A 33-nation study. Science, 332, $1100-1104$.

Gelman, A., Goodrich, B., Gabry, J., \& Vehtari, A. (2019). R-squared for Bayesian regression models. The American Statistician, 73(3), 307-309.

Graham, J., Haidt, J., Koleva, S., Motyl, M., Iyer, R., Wojcik, S. P., \& Ditto, P. H. (2013). Moral foundations theory: The pragmatic validity of moral pluralism. Advances in Experimental Social Psychology, 47, 55-130.

Graham, J., Haidt, J., \& Nosek, B. A. (2009). Liberals and conservatives rely on different sets of moral foundations. Journal of Personality and Social Psychology, 96, 1029-1046.

Graham, J., Nosek, B. A., Haidt, J., Iyer, R., Koleva, S., \& Ditto, P. H. (2011). Mapping the moral domain. Journal of Personality and Social Psychology, 101, 366-385.

Grave, E., Bojanowski, P., Gupta, P., Joulin, A., \& Mikolov, T. (2018). Learning word vectors for 157 languages. In Proceedings of the international conference on language resources and evaluation (LREC 2018).

Greenfield, P. M. (2013). The changing psychology of culture from 1800 through 2000. Psychological Science, 24, 1722-1731. 
Grossmann, I., \& Varnum, M. E. (2015). Social structure, infectious diseases, disasters, secularism, and cultural change in America. Psychological Science, 26, 311-324.

Haidt, J., \& Joseph, C. (2004). Intuitive ethics: How innately prepared intuitions generate culturally variable virtues. Daedalus, 133, 55-66.

Haidt, J., McCauley, C., \& Rozin, P. (1994). Individual differences in sensitivity to disgust: A scale sampling seven domains of disgust elicitors. Personality and Individual Differences, $16,701-713$.

Hanretty, C., Lauderdale, B. E., \& Vivyan, N. (2016). Comparing strategies for estimating constituency opinion from national survey samples. Political Science Research and Methods, 6, 571-591.

Henrich, J., Heine, S. J., \& Norenzayan, A. (2010). The weirdest people in the world? Behavioral and Brain Sciences, 33, 61-83.

Hofstede, G. (2010). National cultural dimensions. Retrieved from https://www.hofstedeinsights.com/country-comparison/

Hoover, J., Atari, M., Davani, A. M., Kennedy, B., Portillo-Wightman, G., Yeh, L., \& Dehghani, M. (2021). Investigating the role of group-based morality in extreme behavioral expressions of prejudice. Nature Communications, 12(1), 1-13.

Hoover, J., \& Dehghani, M. (2020). The big, the bad, and the ugly: Geographic estimation with flawed psychological data. Psychological Methods, 25, 412-429.

Hruschka, D. J., \& Henrich, J. (2013). Institutions, parasites and the persistence of in-group preferences. PLoS One, 8, 1-9. 
Jackson, J. C., Gelfand, M., De, S., \& Fox, A. (2019). The loosening of American culture over 200 years is associated with a creativity-order trade-off. Nature Human Behaviour, 3, 244-250.

Jackson, J. C., Gelfand, M., \& Ember, C. R. (2020). A global analysis of cultural tightness in non-industrial societies. Proceedings of the Royal Society B, 287(1930), 20201036.

Jackson, J. C., Watts, J., List, J.-M., Puryear, C., Drabble, R., \& Lindquist, K. A. (2021). From Text to Thought: How Analyzing Language Can Advance Psychological Science. Perspectives on Psychological Science. In press.

Karimi-Malekabadi, F., Reimer, N. K., Atari, M., Trager, J., Kennedy, B., Graham, J., \& Dehghani, M. (2021). Moral Values Predict County-Level COVID-19 Vaccination Rates in the United States. https://doi.org/10.31234/osf.io/z6kxm

Kim, H. S., Sherman, D. K., \& Updegraff, J. A. (2016). Fear of Ebola: The influence of collectivism on xenophobic threat responses. Psychological Science, 27, 935-944.

Kivikangas, J. M., Fernández-Castilla, B., Järvelä, S., Ravaja, N., \& Lönnqvist, J.-E. (2021). Moral foundations and political orientation: Systematic review and meta-analysis. Psychological Bulletin, 147(1), 55-94.

Leemann, L., \& Wasserfallen, F. (2017). Extending the use and prediction precision of subnational public opinion estimation: Extending use and precision of MrP. American Journal of Political Science, 61, 1003-1022.

Michel, J.-B., Shen, Y. K., Aiden, A. P., Veres, A., Gray, M. K., Pickett, J. P., . . Aiden, E. L. (2011). Quantitative analysis of culture using millions of digitized books. Science, 331, 176-182. 
Mikolov, T., Sutskever, I., Chen, K., Corrado, G. S., \& Dean, J. (2013). Distributed representations of words and phrases and their compositionality. In Advances in Neural Information Processing Systems (pp. 3111-3119).

Misra, S., Le, P. D., Goldmann, E., \& Yang, L. H. (2020). Psychological impact of anti-Asian stigma due to the COVID-19 pandemic: A call for research, practice, and policy responses. Psychological Trauma: Theory, Research, Practice, and Policy, 12(5), 461-464.

MIT Election Data and Science Lab. (2018). County presidential election returns 2000-2016. Harvard Dataverse. doi: 10.7910/DVN/VOQCHQ

Morris, M., Wheeler-Martin, K., Simpson, D., Mooney, S. J., Gelman, A., \& DiMaggio, C. (2019). Bayesian hierarchical spatial models: Implementing the Besag York Mollié model in Stan. Spatial and Spatio-Temporal Epidemiology, 31, 100301.

Mortensen, C. R., Becker, D. V., Ackerman, J. M., Neuberg, S. L., \& Kenrick, D. T. (2010). Infection breeds reticence: The effects of disease salience on self-perceptions of personality and behavioral avoidance tendencies. Psychological Science, 21, 440-447.

Murray, D. R., Kerry, N., \& Gervais, W. M. (2019). On disease and deontology: Multiple tests of the influence of disease threat on moral vigilance. Social Psychological and Personality Science, 10, 44-52.

Murray, D. R., \& Schaller, M. (2010). Historical prevalence of infectious diseases within 230 geopolitical regions: A tool for investigating origins of culture. Journal of Cross-Cultural Psychology, 41, 99-108.

Murray, D. R., \& Schaller, M. (2016). The behavioral immune system: Implications for social cognition, social interaction, and social influence. Advances in Experimental Social Psychology, 53, 75-129. 
Murray, D. R., Schaller, M., \& Suedfeld, P. (2013). Pathogens and politics: Further evidence that parasite prevalence predicts authoritarianism. PLoS One, 8, e62275.

Muthukrishna, M., Bell, A., Henrich, J., Curtin, C., Gedranovich, A., McInerney, J., \& Thue, B. (2020). Beyond western, educated, industrial, rich, and democratic (WEIRD) psychology: Measuring and mapping scales of cultural and psychological distance. Psychological Science, 31, 678-701.

Muthukrishna, M., Henrich, J., \& Slingerland, E. (2021). Psychology as a historical science. Annual Review of Psychology, 72, 717-749.

Navarrete, C. D., \& Fessler, D. M. (2006). Disease avoidance and ethnocentrism: The effects of disease vulnerability and disgust sensitivity on intergroup attitudes. Evolution and Human Behavior, 27, 270-282.

Neuberg, S. L., Kenrick, D. T., \& Schaller, M. (2011). Human threat management systems: Selfprotection and disease avoidance. Neuroscience \& Biobehavioral Reviews, 35, 1042-1051.

Oyserman, D., Coon, H. M., \& Kemmelmeier, M. (2002). Rethinking individualism and collectivism: Evaluation of theoretical assumptions and meta-analyses. Psychological Bulletin, 128, 3-72.

Park, D. K., Gelman, A., \& Bafumi, J. (2004). Bayesian multilevel estimation with poststratification: State-level estimates from national polls. Political Analysis, 12, 375385.

Perone, P., Becker, D. V., \& Tybur, J. M. (2021). Visual disgust elicitors produce an attentional blink independent of contextual and trait-level pathogen avoidance. Emotion, 21(4), 871880. 
Riebler, A., Sørbye, S. H., Simpson, D., \& Rue, H. (2016). An intuitive Bayesian spatial model for disease mapping that accounts for scaling. Statistical Methods in Medical Research, $25,1145-1165$.

Rozin, P., Haidt, J., \& McCauley, C. R. (2008). Disgust. In M. Lewis, J. M. Haviland-Jones, \& L. F. Barret (Eds.), Handbook of emotions (pp. 757-776). New York, NY, US: The Guilford Press.

Schaller, M. (2006). Parasites, behavioral defenses, and the social psychological mechanisms through which cultures are evoked. Psychological Inquiry, 17, 96-101.

Schaller, M., \& Murray, D. R. (2011). Infectious disease and the creation of culture. In M. Gelfand, C.-Y. Chiu, \& Y.-Y. Hong (Eds.), Advances in culture and psychology (Vol. 1, pp. 99-151). New York: Oxford University Press.

Schaller, M., \& Park, J. H. (2011). The behavioral immune system (and why it matters). Current Directions in Psychological Science, 20, 99-103.

Schmid-Hempel, P. (2003). Variation in immune defence as a question of evolutionary ecology. Proceedings of the Royal Society of London. Series B: Biological Sciences, 270, 357-366.

Selb, P., \& Munzert, S. (2011). Estimating constituency preferences from sparse survey data using auxiliary geographic information. Political Analysis, 19, 455-470.

Seth, A. K., Barrett, A. B., \& Barnett, L. (2015). Granger causality analysis in neuroscience and neuroimaging. Journal of Neuroscience, 35, 3293-3297.

Sng, O., Neuberg, S. L., Varnum, M. E., \& Kenrick, D. T. (2018). The behavioral ecology of cultural psychological variation. Psychological Review, 125(5), 714.

Snowden, F. M. (2019). Epidemics and society: From the black death to the present. Yale University Press. 
Stan Development Team. (2021). RStan: The R interface to Stan. Retrieved September 9, 2021, from http://mc-stan.org/

Tanaka, M. M., Kumm, J., \& Feldman, M. W. (2002). Coevolution of pathogens and cultural practices: A new look at behavioral heterogeneity in epidemics. Theoretical Population Biology, 62, 111-119.

Thompson, E. R. (2007). Development and validation of an internationally reliable short-form of the positive and negative affect schedule (PANAS). Journal of Cross-Cultural Psychology, $38,227-242$.

Thornhill, R., \& Fincher, C. L. (2014). The parasite-stress theory of values and sociality: Infectious disease, history and human values worldwide. Springer International Publishing Switzerland.

Tybur, J. M., Inbar, Y., Aarøe, L., Barclay, P., Barlow, F. K., de Barra, M., . . Žeželj, I. (2016). Parasite stress and pathogen avoidance relate to distinct dimensions of political ideology across 30 nations. Proceedings of the National Academy of Sciences, 113, 12408-12413.

Tybur, J. M., Lieberman, D., Kurzban, R., \& DeScioli, P. (2013). Disgust: Evolved function and structure. Psychological Review, 120, 65-84.

Uz, I. (2015). The index of cultural tightness and looseness among 68 countries. Journal of Cross-Cultural Psychology, 46, 319-335.

Van Leeuwen, F., Park, J. H., Koenig, B. L., \& Graham, J. (2012). Regional variation in pathogen prevalence predicts endorsement of group-focused moral concerns. Evolution and Human Behavior, 33, 429-437.

Wagemans, F., Brandt, M. J., \& Zeelenberg, M. (2018). Disgust sensitivity is primarily associated with purity-based moral judgments. Emotion, 18, 277-289. 
Wilcox, R. R., \& Tian, T. S. (2011). Measuring effect size: a robust heteroscedastic approach for two or more groups. Journal of Applied Statistics, 38, 1359-1368.

Yazdanbakhsh, M., Kremsner, P. G., \& Van Ree, R. (2002). Allergy, parasites, and the hygiene hypothesis. Science, 296, 490-494.

Yilmaz, O., \& Saribay, S. A. (2017). Activating analytic thinking enhances the value given to individualizing moral foundations. Cognition, 165, 88-96. 